\title{
Internal mammary artery versus saphenous vein graft Comparative performance in patients with combined revascularisation
}

\author{
RAM N SINGH, JULIO A SOSA, GEORGE E GREEN \\ From University of Pittsburgh School of Medicine, and Cardiac Catheterization Laboratory, Montefiore Hospital, \\ Pittsburgh, Pennsylvania; Albany Medical College and Adult Catheterization Laboratory, Albany Medical Center \\ Hospital, Albany, New York; and Columbia University College of Physicians and Surgeons, and Long Island \\ fewish-Hillside Medical Center, New Hyde Park, New York, USA
}

SUMMARY Thirty three patients with coronary artery disease undergoing combined myocardial revascularisation with internal mammary artery and saphenous vein grafts underwent angiographic studies up to 10 years after operation. Each patient had one internal mammary artery graft and one or more saphenous vein grafts. Eleven symptom-free patients, studied one month to five years (mean 1.9 years) after operation, had intact internal mammary artery and saphenous vein grafts in a good state of preservation. Of the six patients developing symptoms within the first year after surgery, three had evidence of poor flow in the internal mammary artery graft because of large side branches and the other three had stenosis or occlusion of the saphenous vein grafts. Sixteen patients developed symptoms after several years free of symptoms and were studied three to 10 years (mean six years) after operation. Of the 23 saphenous vein grafts in this group, $17(74 \%)$ were either occluded or severely stenosed and six $(26 \%)$ were in good condition. One internal mammary artery graft was occluded and the remaining 15 were in good condition. Saphenous vein graft failure was the predominant cause of late development of symptoms in patients with combined revascularisation. Long term performance of the internal mammary artery grafts is far superior to the saphenous vein grafts.

Direct myocardial revascularisation occupies an important place in the management of symptomatic coronary artery disease. Both the saphenous vein and internal mammary artery have been used as bypass grafts, but their comparative efficacy has been a subject of controversy. The internal mammary artery grafts deliver a smaller flow compared with saphenous vein grafts $^{12}$ and this has led some to believe that they are adequate only for small arteries with poor runoff. ${ }^{3}$ Others believe that the flow offered by internal mammary artery grafts is adequate for coronary revascularisation. ${ }^{45}$ This is supported by good performance on postoperative exercise testing of patients with internal mammary artery grafts. ${ }^{6}$ In one long term clinical follow-up study, ${ }^{7}$ the patients with internal mammary artery grafts fared better than those with saphenous

Accepted for publication 15 March 1982 vein grafts in terms of relief of symptoms and survi$\mathrm{val}$. In another large study of patients with single and multiple grafts, better survival was attributed to complete revascularisation and the use of internal mammary artery grafts. ${ }^{8}$ In this study, the one year patency rate was $95 \%$ for internal mammary artery grafts and $82 \%$ for saphenous vein grafts. Similar results are reported in another study. 9

The studies comparing the results of the internal mammary artery and saphenous vein grafts ${ }^{31011}$ have been done on different series of unmatched patients and the angiographic follow-up has averaged less than two years.

In the past decade a number of patients have undergone combined revascularisation, that is simultaneous use of an internal mammary artery graft and saphenous vein graft in the same patient. These patients are excellent models for studying comparative performance of the two conduits because the 
host factors and surgical technique remain constant. An exclusive study on such patients has not been reported.

The present report is based on analysis of clinical and angiographic data on 33 patients with combined revascularisation, studied up to 10 years after operation. The data were analysed to determine the patency as well as the state of preservation of the two types of grafts in individual patients, and their comparative role in causing symptoms.

\section{Subjects and methods}

\section{STUDY SUBJECTS}

Clinical records and catheterisation data of all patients with combined myocardial revascularisation, who have undergone angiographic studies since January 1976 at the Montefiore Hospital, Pittsburgh, and Albany Medical Center Hospital, were reviewed. These consisted of 33 male patients, 39 to 72 years of age, studied one month to 10 years after operation. All the patients had undergone preoperative coronary arteriography by the authors. All the major vessels with greater than $70 \%$ constriction and a good runoff were bypassed. Arteries with arteriographically estimated lumen of less than $1.5 \mathrm{~mm}$ were not grafted. A total of $\mathbf{8 1}$ grafts was constructed, giving an average of 2.5 grafts per patient. Each patient received a left internal mammary artery graft and one or more saphenous vein grafts. Of the 33 internal mammary artery grafts, 31 were placed on the left anterior descending coronary artery and two on the diagonal branches. Of the 48 saphenous vein grafts, 21 were placed on the right coronary artery, 22 on the left circumflex coronary artery, two on the left anterior descending coronary artery, and three on the diagonal branches. If two anterolateral arteries (left anterior descending and diagonal) were bypassed in the same patient, the saphenous vein graft was used for the artery with the larger runoff and the internal mammary artery graft for the artery with a smaller runoff.

The postoperative angiographic studies were done on $35 \mathrm{~mm}$ cine film at 30 frames per second using a Phillips six-inch image intensifier. In each case, the study included selective coronary arteriography, left ventricular angiography, and selective angiography of the internal mammary artery and saphenous vein grafts in multiple oblique projections. The occluded grafts were also selectively cannulated and the "stump" opacified in each case (Fig. 2B, 3B). In the analysis of the angiographic studies, attention was paid to the native circulation as well as the grafts, and symptoms were correlated with the arteriographic findings. If significant disease (greater than $70 \%$ ) was present in the ungrafted artery or distal segment of the grafted artery, the findings were compared with the preoperative study. Progression of coronary artery disease was defined as a change in stenosis, less than $70 \%$ at preoperative catheterisation to a stenosis of greater than $70 \%$ at the postoperative study. For the purpose of this study, the occlusion of the proximal lesion in the grafted coronary artery was not considered a progression of disease. Angiographic appearance of the internal mammary artery and saphenous vein grafts was carefully studied in their entire length, including the anastomotic sites, for luminal irregularities and obstructions. The diameter of the graft just proximal to the anastomosis was compared to the grafted artery distal to the anastomosis.

The condition of the saphenous vein grafts was graded " 0 " to " ++++ " in the following manner: (1) smooth contour $(++++)$; (2) irregular contour without constrictions $(+++)$; (3) constriction(s) reducing lumen by less than $70 \%(++)$; (4) constriction(s) reducing lumen by more than $70 \%(+) ;(5)$ occluded (0). The examples are illustrated in Fig. 1 to 3.

For the internal mammary artery grafts, attention was paid to any large side branches and associated attenuation of the distal internal mammary artery lumen. This phenomenon indicates diversion of flow and has been described in detail in a previous report. ${ }^{12}$ The graft flow was considered poor only if the diameter of the distal internal mammary artery was less than two-thirds of the proximal and measured less than the grafted coronary artery. The condition of the internal mammary artery graft was considered excellent if the lumen was smooth, with the distal diameter greater than $2 \mathrm{~mm}$, and there was good filling of the grafted coronary artery.

\section{VEIN GRAFTS TO LEFT ANTERIOR DESCENDING CORONARY ARTERY}

In the study subjects the left anterior descending coronary artery almost routinely received the internal mammary artery grafts, so that the question of performance of vein grafts to this vessel arises. For this purpose, the records of all the patients receiving saphenous vein grafts to the left anterior descending coronary artery, who underwent postoperative angiographic studies at both the participating laboratories since January 1976, were reviewed. There were 43 patients studied two weeks to 10 years after operation. All these patients had undergone preoperative studies in the same laboratory. They were operated upon in the same time period as the study subjects by the same surgical teams. 

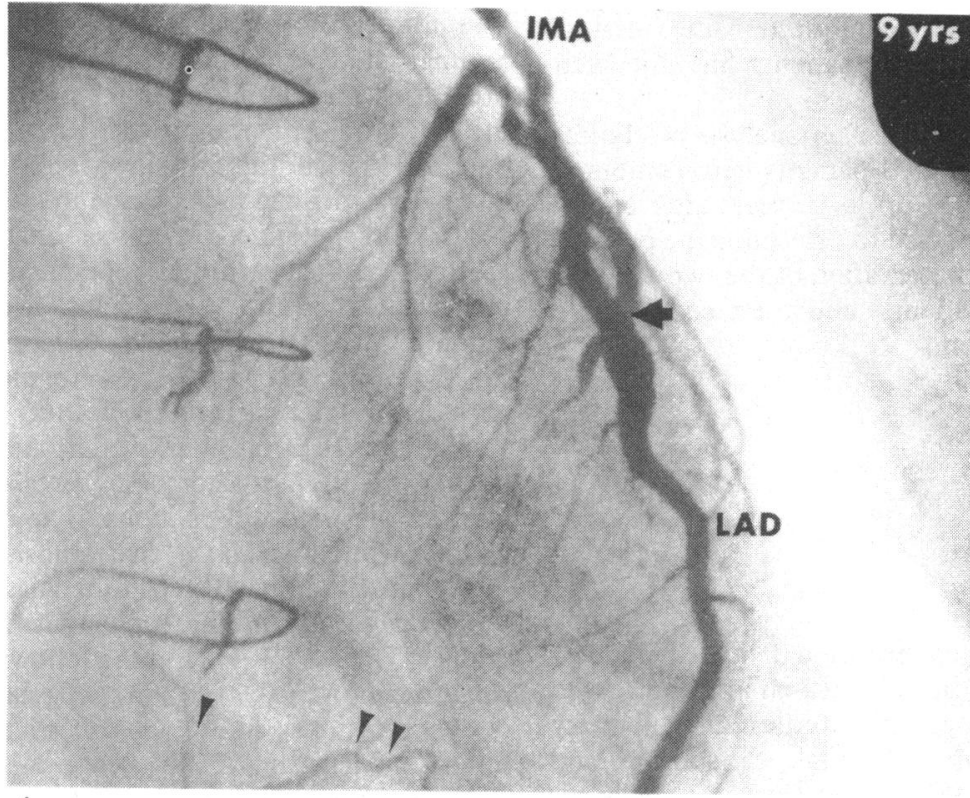

$A$

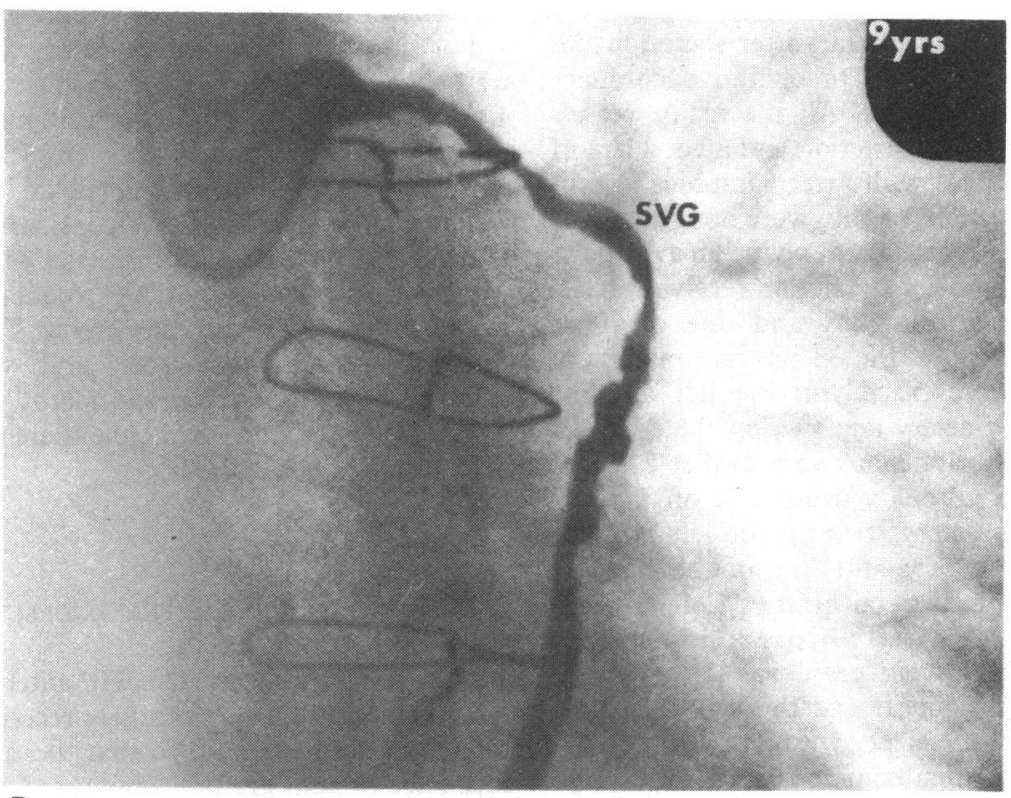

Fig. 1 Nine year' postoperative angiographic study. (A) Distal part of the left internal mammary artery grafi (IMA) showing excellent filling of the grafted left anterior descending coronary artery (LAD). Collateral filling of the distal lefi circumflex artery (arrow heads) is also seen. (B) Proximal part of the saphenous vein grafi (SVG) to the left circumflex coronary artery in poor condition $(+)$ with multiple constrictions. Distal nunoff (not shown) was excellent. 


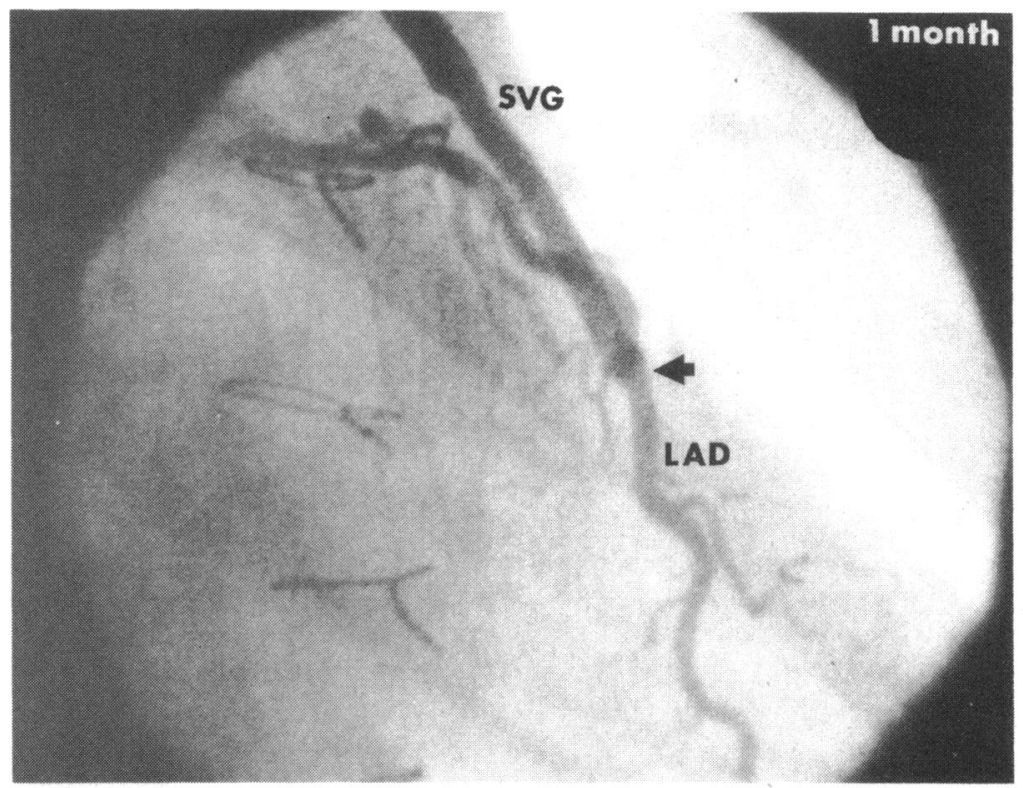

$A$

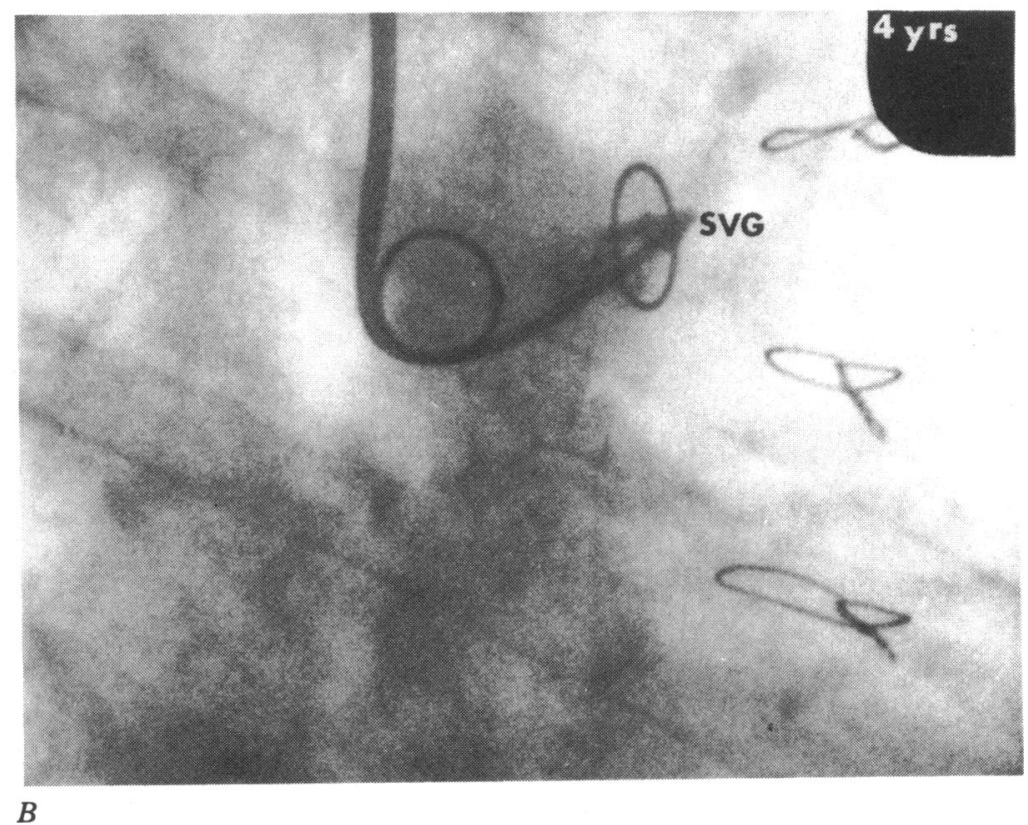

Fig. 2 Serial angiographic studies one month and four years after operation. (A) Distal part of the saphenous vein graft (SVG) to the left anterior descending coronary artery (LAD) showing the graft in excellent condition $(++++)$ with a large runoff. (B) Occluded aortic end of the same grafi (SVG) four years later. 
IMA

Diag

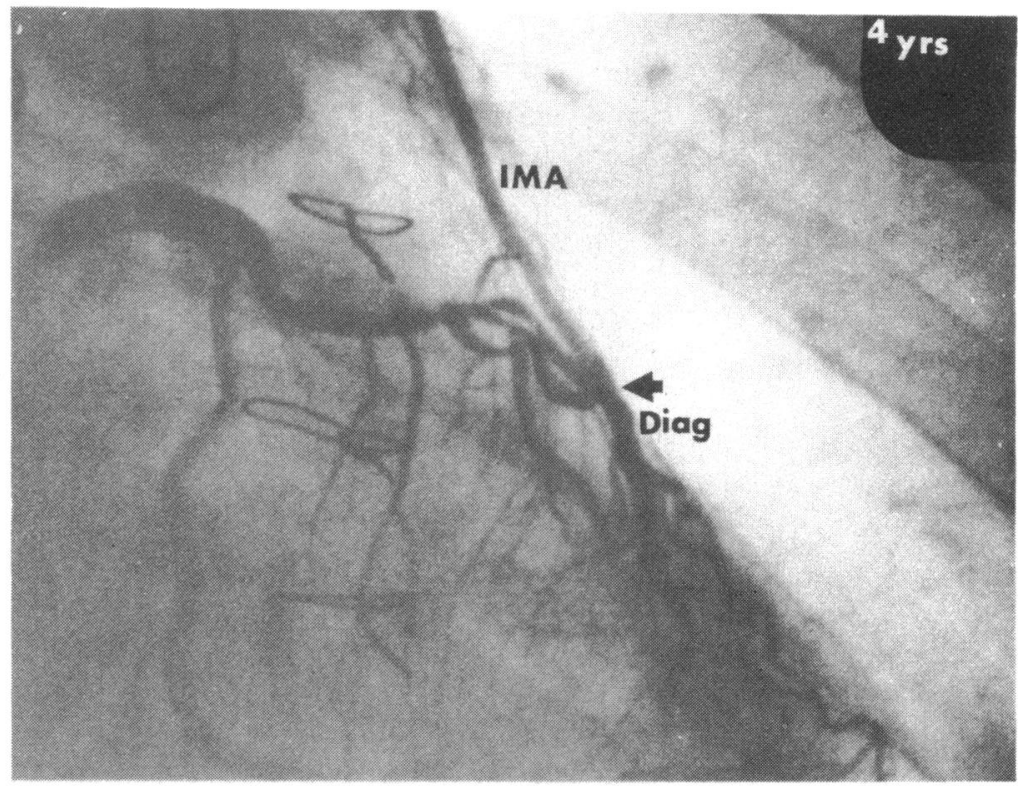

D

Fig. 2(cont) Serial angiographic studies one month and four years after operation. (C) Distal part of the left internal mammary artery graft (IMA) to the diagonal branch (Diag) showing a limited runoff. (D) Same graft (IMA) filling the entire lefi coronary system four years later. 


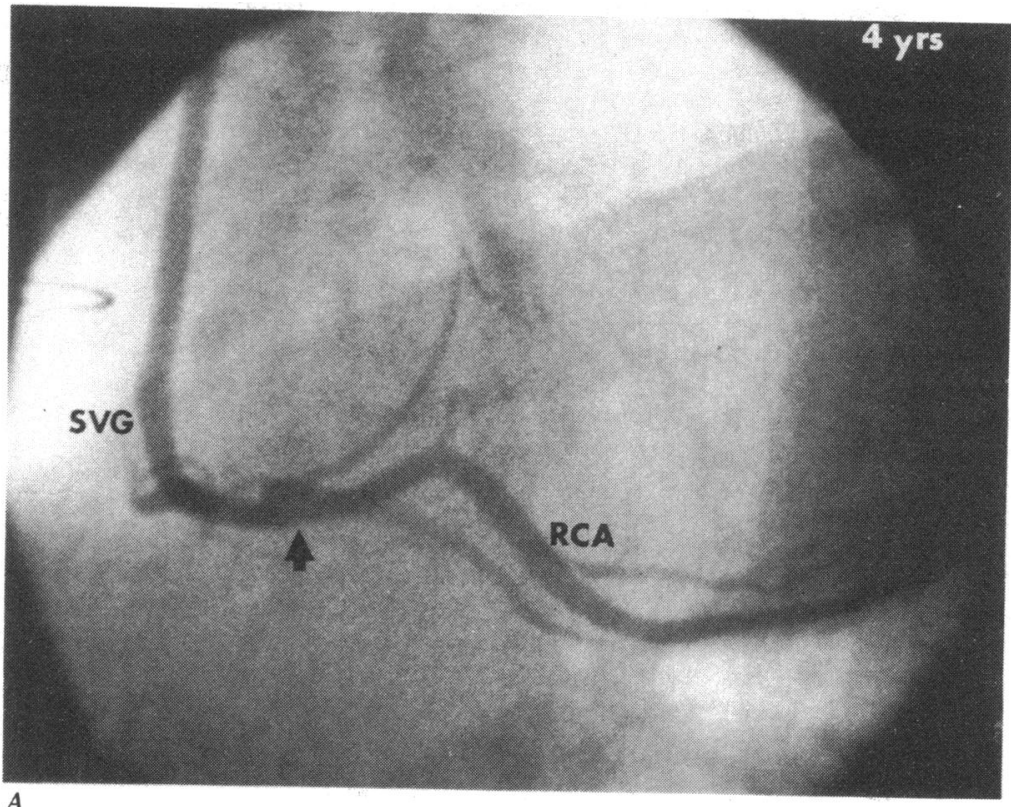

A

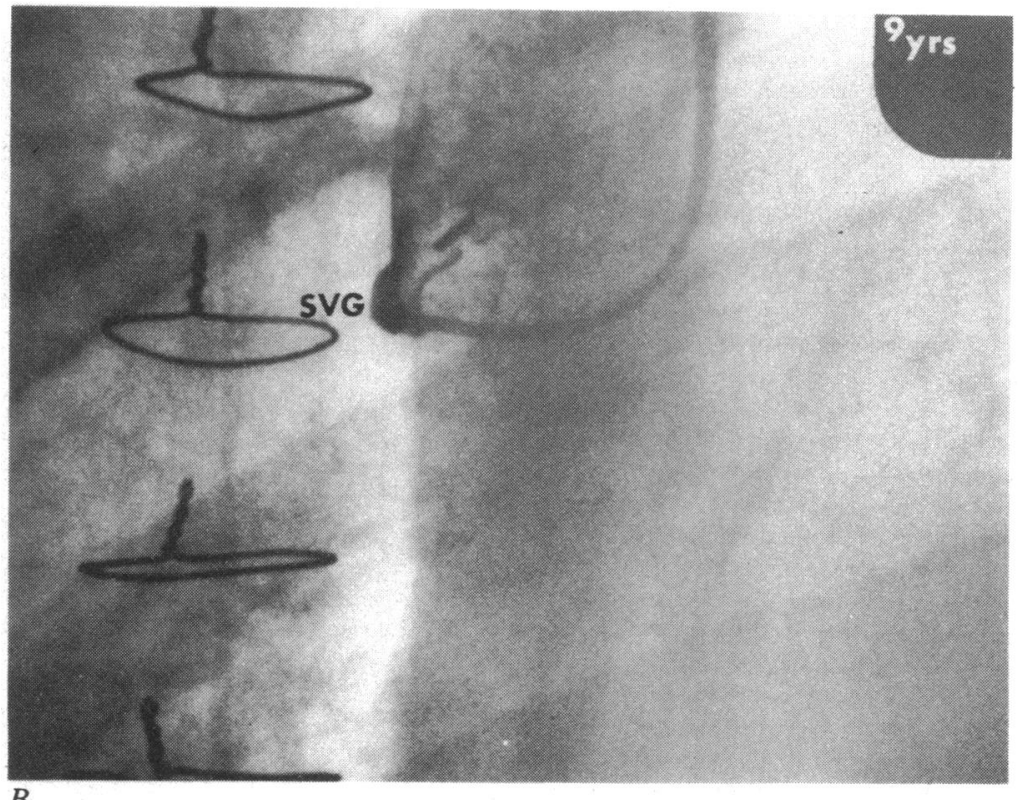

Fig. 3 Serial angiographic studies four and nine years after operation. (A) Distal part of the saphenous vein grafi (SVG) to the right coronary artery (RCA) showing the graft in excellent condition $(++++)$ with a large runoff. $(B)$ Occluded aortic end of the same graft (SVG) five years later. 
Singh, Sosa, Green

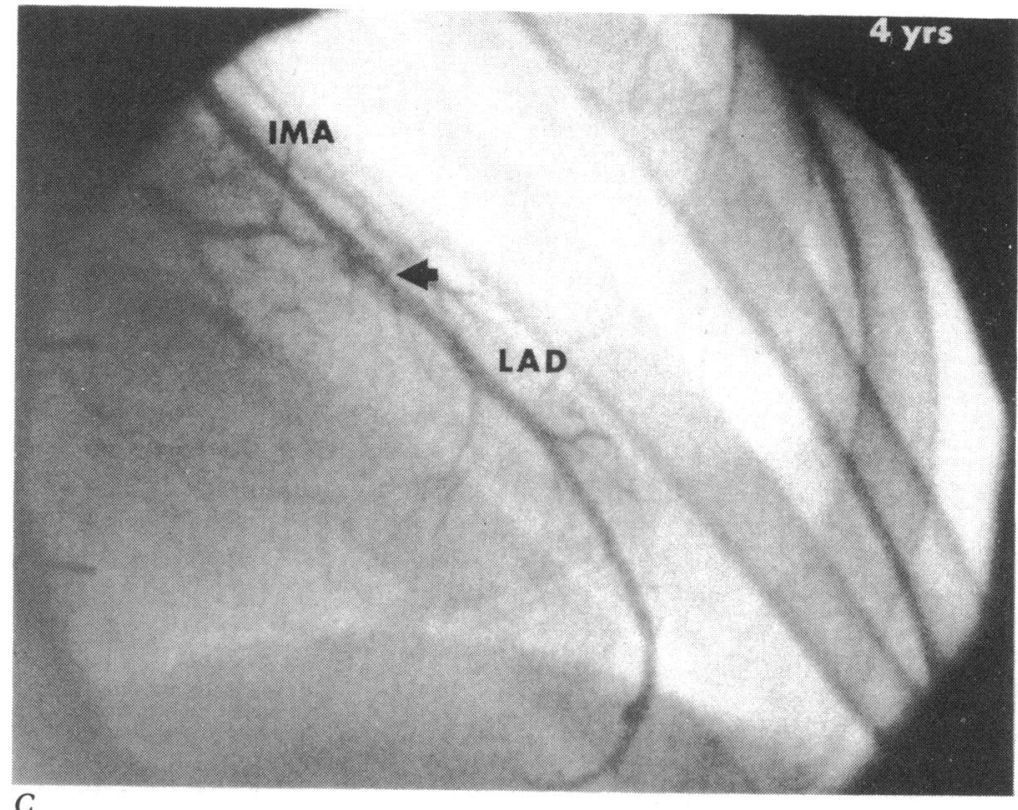

$C$

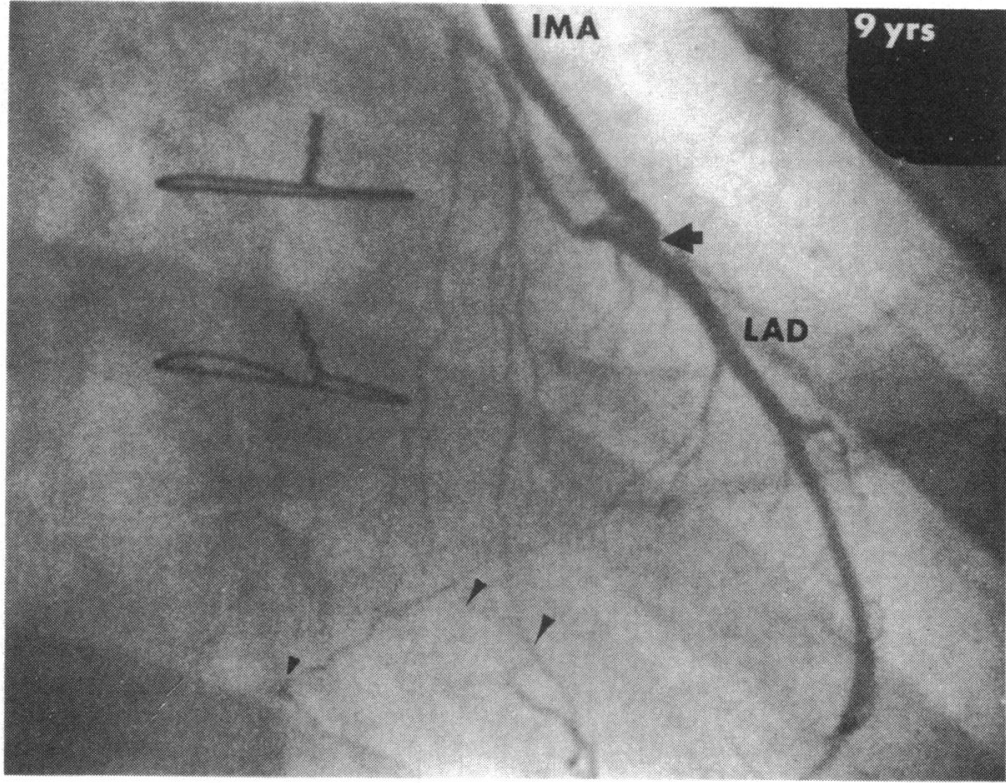

$D$

Fig. 3 (cont) Serial angiographic studies four and nine years after operation. (C) Distal part of the left internal mammary artery graft (IMA) to the left anterior descending coronary $\operatorname{artery}(L A D)$. (D) The same graft is seen well preserved five years later. Collaterals (arrow heads) to the right coronary artery are also seen. 


\section{Results}

The patient population was divided into three groups.

\section{GROUP 1: PATIENTS WITHOUT SYMPTOMS}

These 11 patients were studied one month to five years (mean 1.9 years) after operation. The majority underwent angiography as a part of another study. ${ }^{13}$ In this group all 11 internal mammary artery grafts were in good condition with good flow. All 17 saphenous vein grafts were patent; 16 were in good condition $(+++$ to ++++$)$ and one was in fair condition with $50 \%$ constriction $(++)$. There was no progression of atherosclerosis in the native coronary circulation.

\section{GROUP 2: PATIENTS WITH EARLY SYMPTOMS}

These six patients developed angina on effort within the first year after operation. Three of the six internal mammary artery grafts were in good condition with good flow. The other three had large side branches associated with attenuation of the distal internal mammary artery lumen measuring less than the grafted coronary artery, fulfilling the criteria for poor graft flow. This was the probable cause of symptoms in these three cases. Out of the eight saphenous vein grafts, five were in good condition $(+++$ to ++++$)$; one was in fair condition $(++)$ with distal kinking; one had stenosis $(+)$ at the distal anastomosis, and one was occluded. There was no progression of atherosclerosis in the native circulation.
GROUP 3: PATIENTS WITH LATE SYMPTOMS

These 16 patients developed symptoms after several years symptom free and were studied three to 10 years (mean six years) after operation (Table). The symptoms included angina, myocardial infarction, or both. One internal mammary artery graft was occluded proximally (case 11) and the other 15 were patent and in excellent condition. Sixteen patients in this group had 23 saphenous vein grafts. Eleven were totally occluded and six were in poor condition $(t)$. Thus only six grafts (26\%) were in good condition. In 13 out of 16 patients $(81 \%)$, stenosis or occlusion of the saphenous vein grafts appeared to be the cause of symptoms. Three patients in this group (19\%) had developed progression of atherosclerosis in the ungrafted arteries which could be considered responsible for the symptoms.

\section{SERIAL ANGIOGRAPHIC STUDIES}

In three patients serial angiographic studies were available for comparison (Fig. 2 and 3). In the first postoperative study, all the saphenous vein grafts were in excellent condition $(++++)$. In the second postoperative study, one saphenous vein graft had developed $90 \%$ stenosis and three were totally occluded. There were no apparent clues to this outcome. In the late studies, there was enlargement of the distal internal mammary artery lumen associated with perfusion of a larger coronary bed (Fig. 2D, 3D).

Table Patients with late development of symptoms

\begin{tabular}{|c|c|c|c|c|c|}
\hline \multirow[t]{2}{*}{ Case No. } & \multirow[t]{2}{*}{ Time after surgery } & \multicolumn{2}{|c|}{ Saphenous vein graft } & \multicolumn{2}{|l|}{ IMA graft } \\
\hline & & Grafied artery & Condition & Grafted artery & Condition \\
\hline 1 & $3 y$ & $\begin{array}{l}\text { RCA } \\
\text { LCx }\end{array}$ & $\begin{array}{l}+ \\
+++\end{array}$ & LAD & $+++t$ \\
\hline $\begin{array}{l}2 \\
3 \\
4\end{array}$ & $\begin{array}{l}3 \mathrm{y} \\
3.5 \mathrm{y} \\
3.5 \mathrm{y}\end{array}$ & $\begin{array}{l}\text { LCx } \\
\text { LCx } \\
\text { LCx } \\
\text { Diagonal }\end{array}$ & $\begin{array}{l}0 \\
0 \\
0 \\
0\end{array}$ & $\begin{array}{l}\text { LAD } \\
\text { LAD } \\
\text { LAD }\end{array}$ & $\begin{array}{l}++++ \\
++++ \\
++++\end{array}$ \\
\hline $\begin{array}{l}5 \\
6\end{array}$ & $\begin{array}{l}3.5 y \\
4 y\end{array}$ & $\begin{array}{l}\text { LCx } \\
\text { RCA } \\
\text { LAD }\end{array}$ & $\begin{array}{l}+ \\
0 \\
0\end{array}$ & $\begin{array}{l}\text { LAD } \\
\text { Diagonal }\end{array}$ & $\begin{array}{l}+++ \\
++++\end{array}$ \\
\hline 7 & $4 y$ & $\begin{array}{l}\text { RCA } \\
\text { LCx }\end{array}$ & $\begin{array}{l}++++ \\
+++\end{array}$ & LAD & +++ \\
\hline $\begin{array}{l}8 \\
9\end{array}$ & $\begin{array}{l}5 y \\
6 y\end{array}$ & $\begin{array}{l}\text { RCA } \\
\text { RCA } \\
\text { LCx }\end{array}$ & $\begin{array}{l}+++ \\
0 \\
0\end{array}$ & $\begin{array}{l}\text { LAD } \\
\text { LAD }\end{array}$ & $\begin{array}{l}+++ \\
+++t\end{array}$ \\
\hline 10 & $7 y$ & $\begin{array}{l}\text { RCA } \\
\text { LCx }\end{array}$ & $\begin{array}{l}+ \\
+++\end{array}$ & LAD & +++ \\
\hline $\begin{array}{l}11 \\
12\end{array}$ & $\begin{array}{l}7 \mathrm{y} \\
9 \mathrm{y}\end{array}$ & $\begin{array}{l}\text { LCx } \\
\text { RCA } \\
\text { LCx }\end{array}$ & $\begin{array}{l}+ \\
+ \\
0\end{array}$ & $\begin{array}{l}\text { LAD } \\
\text { LAD }\end{array}$ & $\begin{array}{l}0 \\
+++\end{array}$ \\
\hline $\begin{array}{l}13 \\
14 \\
15 \\
16\end{array}$ & $\begin{array}{l}9 y \\
9 y \\
9 y \\
10 y\end{array}$ & $\begin{array}{l}\text { LCx } \\
\text { RCA } \\
\text { LCx } \\
\text { LCx }\end{array}$ & $\begin{array}{l}++++ \\
0 \\
+ \\
0\end{array}$ & $\begin{array}{l}\text { LAD } \\
\text { LAD } \\
\text { LAD } \\
\text { LAD }\end{array}$ & $\begin{array}{l}++++ \\
++++ \\
++++ \\
++++\end{array}$ \\
\hline
\end{tabular}

RCA, right coronary artery; LCx, left circumflex artery; LAD, left anterior descending artery; IMA, internal mammary artery; condition of RCA, right coronary artery; LCx, left circumfex artery; LAD, left anter $(0)$.
grafts: excellent $(++++)$; good $(+++)$; fair $(++)$; poor $(+)$; occluded $(t)$ 
GRAFT DIAMETERS

Excluding three patients with attenuated internal mammary artery grafts, the average graft/artery diameter ratio was 1.2 for 29 patent internal mammary artery grafts. For the 36 patent saphenous vein grafts, the average graft/artery diameter ratio was 1.8.

\section{LEFT ANTERIOR DESCENDING ARTERY GRAFTS: INTERNAL MAMMARY ARTERY VS SAPHENOUS VEIN GRAFT}

In the entire study population, 32 of the 33 internal mammary artery grafts were patent at a mean follow up period of 3.6 years (patency $97 \%$ ). In the series of saphenous vein grafts to left anterior descending coronary artery, 27 of the $\mathbf{4 3}$ grafts were patent at a mean follow up period of 3.1 years (patency 63\%). The difference in the patency rates is statistically significant $(p<0.005)$.

\section{Discussion}

Other studies evaluating the postoperative results have shown a good correlation between relief of symptoms and completeness of myocardial revascularisation ${ }^{14}$ as well as graft patency. ${ }^{15}$ The grafts not only have to be patent but must deliver sufficient flow to meet the myocardial oxygen demands. Our findings in the group 1 patients indicate that in the symptom free patients both the internal mammary artery grafts and saphenous vein grafts can be expected to be functioning. The findings in group 2 patients show that the problems with internal mammary artery grafts and saphenous vein grafts are equally common in patients presenting with symptoms soon after operation. On the other hand, in the patients with late symptoms, saphenous vein graft failure is predominant.

\section{FAILURE OF SAPHENOUS VEIN GRAFTS}

Early saphenous vein graft failure appears to be related to errors of judgment and technique. ${ }^{15}$ This includes grafting of the coronary arteries with mild proximal lesions or poor distal runoff. ${ }^{16}$ Kinking or stenosis at the anastomotic sites (Fig. 1A) are examples of technical failure. First year occlusion rates of 10 to $30 \%$ have been reported. 1517 With good patient selection and improved surgical techniques, this is probably less common today.

In serial angiographic studies, ${ }^{15-18}$ the grafts that were open early appeared to maintain patency in the $80 \%$ range at four to six years. In the late studies, however, different degrees of occlusive changes were seen in some of the grafts. ${ }^{18} 19$ The atherosclerotic nature of these changes has been confirmed in the grafts removed at reoperation. 161819 These changes are variable in onset and progression, ${ }^{18}$ and may lead to late graft failure. Again, there is good correlation between symptoms and graft occlusion. In an average follow-up of two and a half years, Hamby et al. ${ }^{15}$ found an annual graft attrition rate of $6.5 \%$ in patients with symptoms and $1 \cdot 1 \%$ in patients without symptoms. Our finding of a high incidence of graft stenosis and occlusion in group 3 patients appears to be an extension of this trend and attests to the progressive nature of atherosclerosis in the saphenous vein grafts. The stable clinical course for the first few years does not mean stabilisation of the intimal proliferative process in the vein grafts. We agree with Guthaner et al. ${ }^{18}$ that the continued stability of a vein graft cannot be predicted from an early angiographic appearance (Fig. 2 and 3).

\section{FAILURE OF INTERNAL MAMMARY ARTERY GRAFTS}

The internal mammary artery graft failures appear to be technically related and tend to occur early. These include injury to the internal mammary artery during its mobilisation from the chest wall, stenosis at the distal anastomosis, ${ }^{3}$ use of an internal mammary artery of inadequate calibre ${ }^{3}$ grafting of a coronary artery with insignificant lesion, 10 and "steal" by the large side branches. ${ }^{12}$ All these are minimised with better judgment and surgical skill.

The arteriographic size of the distal internal mammary artery lumen is a reliable indicator of graft flow. ${ }^{12}$ This has been confirmed by flow studies. ${ }^{3}$ The internal mammary artery is a "live" conduit and within certain limits will adapt to the demands of flow. This is indicated by enlargement seen in the late postoperative studies (Fig. 2D, 3D). If the proximal internal mammary artery lumen is well preserved but the distal lumen is much reduced, the usual cause is diversion of flow into the undivided side branches. ${ }^{12}$ This may occur if the internal mammary artery pedicle is not mobilised adequately. ${ }^{20}$ This was the cause of poor flow in three of the six patients with early symptoms (group 2). We did not find this phemonemon in any of the patients without symptoms.

The mechanism of failure of the only internal mammary artery that was found to be occluded in the late postoperative study remains obscure. Development of atherosclerosis is a possibility. Significant atherosclerosis in the internal mammary arteries, however, is rare. Fears of its prevalence ${ }^{21}$ are exaggerated. We have not seen significant atherosclerosis in the large number of internal mammary arteries studied before 2223 and after operation. This is further supported by two recently published long term studies of the internal mammary artery grafts. ${ }^{24} 25$

\section{PROGRESSION OF ATHEROSCLEROSIS IN NATIVE CIRCULATION}

This is an important consideration in postoperative 
evaluation. We do not consider occlusion of the proximal lesion in a grafted artery to be a true progression of disease. It is an expected event if an artery with a high grade lesion is grafted with a saphenous vein. ${ }^{16} 18$ It is of no consequence if the graft remains patent. We agree with Lytle et al. ${ }^{11}$ that the true anatomical occlusion of the proximal lesion is much less common with internal mammary artery grafting.

We did not find significant atherosclerosis in the distal segments of the grafted coronary arteries perfused by patent grafts even if the grafts were severely stenosed. Similar findings have been reported in other studies. ${ }^{17} 18$ This is therefore unlikely to be a common cause of graft failure.

The incidence of progression of atherosclerosis in the ungrafted coronary arteries will differ depending upon the criteria used to define it. Guthaner et al. ${ }^{18}$ found little difference in the behaviour of lesions less than $75 \%$ in an average follow-up of 76 months. In our patients, we did not find significant progression (from $<70 \%$ to $>70 \%$ ) in the early postoperative studies. In late studies it occurred in $19 \%$ of the patients. The failure of saphenous vein grafts was a much more common cause of symptoms.

\section{COMPARATIVE PROPERTIES OF TWO CONDUITS \\ (1) Size and flow}

The saphenous vein is usually much larger than the coronary arteries and also delivers a large flow. If a large vein is grafted to a small coronary artery, however, the large flow ceases to be an advantage because of turbulence and low velocity of flow. ${ }^{26}$ Better performance of the sequential grafts ${ }^{27}$ is the result of better distribution of flow. For the single grafts; the conduit should ideally be slightly larger than the recipient artery. The internal mammary artery more closely approximates the coronary artery size. ${ }^{28} \mathrm{Our}$ observations confirm greater disparity of graft/artery diameters in the case of saphenous vein grafts compared with the internal mammary artery grafts.

\section{(2) Adaptability}

In the aortocoronary position the saphenous vein usually becomes a rigid fibrous tissue conduit. ${ }^{29}$ The internal mammary artery, on the other hand, is a "live" conduit with functioning smooth muscle. It is capable of autoregulation in response to changes in coronary vascular resistance.

\section{(3) Durability}

When interposed in the aortocoronary position, the saphenous vein undergoes both adaptive and degenerative changes. The medial hypertrophy that sometimes occurs ${ }^{29}$ is an adaptive change. It is probably desirable and constitutes true arterialisation. Intimal proliferation and atherosclerotic plaque for- mation are degenerative changes. ${ }^{29} 30$ This process is variable in location and extent even in different segments of the same graft (Fig. 1B). Progression of atherosclerosis in the vein grafts may lead to late graft failure. The internal mammary artery grafts tend to remain free from the degenerative process. ${ }^{24} 25$ Our observations confirm this for a follow up period of up to 10 years.

\section{(4) Surgical technique}

Ease of surgery is the main reason for the immense popularity of saphenous vein grafting. In addition, abundant length is available for grafting several vessels. Internal mammary artery grafting is technically more demanding and this is why it is shunned by many surgeons. Once the technique is mastered, however, consistently good results follow. There is already a trend towards increasing use of the internal mammary artery graft by surgeons, ${ }^{24}$ from $5.7 \%$ in 1974 to $13 \%$ in 1979 . This trend is likely to continue in the 1980's because of increasing awareness of late saphenous vein graft failure.

In this series, the internal mammary artery was routinely used for anterolateral arteries (left anterior descending coronary artery and diagonal), because of anatomical proximity ${ }^{28}$ In five patients receiving grafts to both the left anterior descending artery and diagonal branches, the internal mammary artery was used for the smaller vessel (Fig. 2C) and the saphenous vein graft for the larger one (Fig. 2A). Yet, the internal mammary artery always remained patent while instances of occlusion were seen in the case of vein grafts (Fig. 2B). Further, a relatively high occlusion rate in our series of left anterior descending coronary artery vein grafts indicates that the fate of saphenous vein grafts placed in the left anterior descending coronary artery is similar to those placed in the other vessels. This is in agreement with other studies. ${ }^{1631}$ It appears, therefore, that it is the conduit and not the vessel grafted that makes the difference.

We conclude that the internal mammary artery is a superior conduit for coronary artery grafting and fares much better than the saphenous vein graft in the long run. Late failure of the saphenous vein grafts appears to be the result of an intimal proliferative process from which the internal mammary artery grafts tend to remain free.

\section{References}

1 Singh H, Flemma RJ, Tector AJ, Lepley D Jr, Walker JA. Direct myocardial revascularization: determinants in the choice of vein graft or internal mammary artery. Arch Surg 1973; 107: 699-703.

2 Flemma RJ, Singh HM, Tector AJ, Lepley D Jr, Frazier 
BL. Comparative hemodynamic properties of vein and mammary artery in coronary bypass operations. Ann Thorac Surg 1975; 20: 619-27.

3 Grondin CM, Lesperance J, Bourassa MB, Campeau L. Coronary artery grafting with the saphenous vein or internal mammary artery: comparison of late results in two consecutive series of patients. Ann Thorac Surg 1975; 20: 605-18.

4 Green GE. Rate of blood flow from the internal mammary artery. Surgery 1971; 70: 809-13.

5 McCormick JR, Kaneko M, Baue AE, Geha AS. Blood flow and vasoactive drug effects in internal mammary and venous bypass grafts. Circulation 1975; 51 [suppl I]: 72-80.

6 Siegel W, Loop FD. Comparison of internal mammary artery and saphenous vein bypass grafts for myocardial revascularization: exercise test and angiographic correlations. Circulation 1976; 54 [suppl III]: 1-3.

7 Jones JW, Ochsner JL, Mills NL, Hughes L. The internal mammary bypass graft: a superior second coronary artery. F Thorac Cardiovasc Surg 1978; 75: 625-31.

8 Loop FD, Irarrazaval MJ, Bredee JJ, Siegel W, Taylor PC, Sheldon WC. Internal mammary artery graft for ischemic heart disease: effect of revascularization on clinical status and survival. Am $\mathcal{F}$ Cardiol 1977; 39: 516-22.

9 Kay EB, Naraghipour H, Beg RA, DeManey M, Tambe A, Zimmerman HA. Internal mammary artery bypass graft. Long-term patency rate and follow-up. Ann Thorac Surg 1974; 18: 269-79.

10 Geha AS, Baue AE. Early and late results of coronary revascularization with saphenous vein and internal mammary artery grafts. Am f Surg 1979; 137: 456-63.

11 Lytle BW, Loop FD, Thurer RL, Groves, LK, Taylor PC, Cosgrove DM. Isolated left anterior descending coronary atherosclerosis: long-term comparison of internal mammary artery and venous autografts. Circulation 1980; 61: 869-74.

12 Singh RN, Sosa JA. Internal mammary artery-coronary artery anastomosis: influence of the side branches on surgical result. F Thorac Cardiooasc Surg 1981; 82: 909-14.

13 National Heart, Lung, and Blood Institute Coronary Artery Surgery Study. American Heart Association Monograph Number 79. Circulation 1981; 63 [suppl I]: $1-82$.

14 Sheldon WC, Rincon G, Pichard AD, Razavi M, Cheanvechai $C$, Loop FD. Surgical treatment of coronary artery disease: pure graft operations, with a study of 741 patients followed 3-7 yr. Prog Cardiooasc Dis 1975; 18: 237-53.

15 Hamby RI, Aintablian A, Handler M, et al. Aortocoronary saphenous vein bypass grafts. Long term patency, morphology and blood flow in patients with patent grafts early after surgery. Circulation 1979; 60: 901-9.

16 Liddle HV. Perspective in coronary artery surgery. $\mathcal{F}$ Thorac Cardiovasc Surg 1981; 81: 1-10.

17 Seides SF, Borer JS, Kent KM, Rosing DR, McIntosh $\mathrm{CL}$, Epstein SE. Long term anatomic fate of coronary artery bypass grafts and functional status of patients five years after operation. $N$ Engl $\mathcal{F}$ Med 1978; 298: 1213-7.

18 Guthaner DF, Robert EW, Alderman EL, Wexler L. Long-term serial angiographic studies after coronary artery bypass surgery. Circulation 1979; 60: 250-9.

19 Uricchio JF, Bentivoglio LG. Patency of saphenous vein grafts five or more years after coronary bypass surgery. Am $\mathcal{Y}$ Med 1978; 65: 619-25.

20 Singh $\mathrm{RN}$, Magovern GJ. Internal mammary graft: improved flow resulting from correction of steal phenomenon. F Thorac Cardiovasc Surg 1982; 84: 146-9.

21 Frazier BL, Flemma RJ, Tector AJ, Korns ME. Atherosclerosis involving the internal mammary artery. Ann Thorac Surg 1974; 18: 305-7.

22 Singh RN. Radiographic anatomy of the internal mammary arteries. Cathet Cardiovasc Diagn 1981; 7: 373-86.

23 Singh RN. Atherosclerosis and the internal mammary arteries. Cardiovasc Intervent Radiol 1983 (In press).

24 Tector AJ, Schmahl TM, Janson B, Kallies JR, Johnson $G$. The internal mammary artery graft. Its longevity after coronary bypass. FAMA 1981; 246: 2181-3.

25 Barner HB, Swartz MT, Mudd JG, Tyras DH. Late patency of the internal mammary artery as a coronary bypass conduit. Ann Thorac Surg 1982; 34: 408-12.

26 Furuse A, Klopp EH, Brawley RK, Gott VL. Hemodynamics of aorta-to-coronary artery bypass. Ann Thorac Surg 1972; 14: 282-93.

27 Sewell WH. Improved coronary vein graft patency rates with side-to-side anastomoses. Ann Thorac Surg 1974; 17: $538-44$.

28 Green GE. Technique of internal mammary-coronary artery anastomosis. $f$ Thorac Cardiovasc Surg 1979; 78: 455-9.

29 Brody WR, Kosek JC, Angell WW. Changes in vein grafts following aorto-coronary bypass induced by pressure and ischemia. I Thorac Cardiovasc Surg 1972; 64: 847-54.

30 Spray TL, Roberts WC. Changes in saphenous vein used as aortocoronary bypass grafts. Am Heart f 1977; 94: $500-16$.

31 Cosgrove DM, Loop FD, Saunders CL, Lytle BW, Kramer JR. Should coronary arteries with less than fifty percent stenosis be bypassed? I Thorac Cardiovasc Surg 1981; 82: 520-30.

Requests for reprints to Dr Ram N Singh, Cardiac Catheterization Laboratory, Montefiore Hospital, 3459 Fifth Avenue, Pittsburgh, Pennsylvania 15213, USA.

\section{Addendum}

Since the preparation of this manuscript, we have studied 14 additional patients with combined revascularisation, who presented with symptoms. Each of these has one or more occluded vein grafts. Thirteen internal mammary artery grafts are in excellent condition and one is occluded. 